\title{
P4HB knockdown induces human HT29 colon cancer cell apoptosis through the generation of reactive oxygen species and inactivation of STAT3 signaling
}

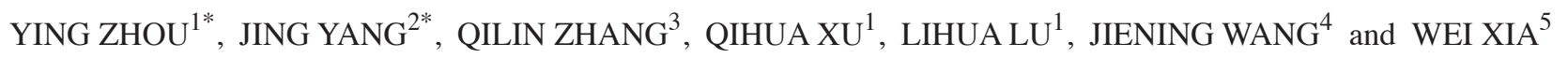 \\ Departments of ${ }^{1}$ Gastroenterology, ${ }^{2}$ General Surgery and ${ }^{3}$ Neurosurgery, Seventh People's Hospital of Shanghai University of \\ Traditional Chinese Medicine; ${ }^{4}$ Department of Integrated TCM and Western Medicine, President's Office; \\ ${ }^{5}$ Department of Nuclear Medicine, Seventh People's Hospital of Shanghai University of \\ Traditional Chinese Medicine, Shanghai 200137, P.R. China
}

Received January 8, 2018; Accepted May 10, 2018

DOI: $10.3892 / \mathrm{mmr} .2018 .9660$

\begin{abstract}
Colon cancer is the second most lethal malignancy worldwide. A better understanding of colon cancer at the molecular level may increase overall survival rates. Previous studies have indicated that prolyl 4-hydroxylase, $\beta$ polypeptide $(\mathrm{P} 4 \mathrm{HB})$ is associated with tumorigenesis in colon cancer; however, its role and molecular mechanisms in colon cancer remain unclear. In the present study, the cellular responses to $\mathrm{P} 4 \mathrm{HB}$ in human colon cancer cell lines were investigated by proliferation and apoptosis assays, western blotting, and immunohistochemistry. The results showed that expression of $\mathrm{P} 4 \mathrm{HB}$ was higher in colon cancer tissues compared within adjacent normal tissues. P4HB knockdown increased the apoptosis of human HT29 cells. Furthermore, P4HB knockdown reduced the activation of signal transducer and activator of transcription 3 (STAT3) and promoted accumulation of reactive oxygen species (ROS). Inhibiting the accumulation of ROS abrogated the increased cell apoptosis induced by P4HB knockdown. Notably, decreased ROS levels effectively antagonized the effects of P4HB on STAT3 inactivation. In conclusion, these findings suggested that P4HB knockdown may induce HT29
\end{abstract}

Correspondence to: Dr Wei Xia, Department of Nuclear Medicine, Seventh People's Hospital of Shanghai University of Traditional Chinese Medicine, 358 Datong Road, Shanghai 200137, P.R. China E-mail: zy226226@126.com

Dr Jiening Wang, Department of Integrated TCM and Western Medicine, President's Office, Seventh People's Hospital of Shanghai University of Traditional Chinese Medicine, 358 Datong Road, Shanghai 200137, P.R. China

E-mail: 1902852942@qq.com

*Contributed equally

Key words: prolyl 4-hydroxylase, $\beta$ polypeptide, colon cancer, reactive oxygen species, apoptosis, signal transducer and activator of transcription 3 human colon cancer cell apoptosis through the generation of ROS and inactivation of the STAT3 signaling pathway.

\section{Introduction}

Colon cancer is the second most lethal malignancy worldwide, which is associated with $>600,000$ cases of mortality per year (1). It is estimated that there are $>1.4$ million people living in the United States with this disease, and an additional 134,490 cases are diagnosed annually (2). Clinicians are faced with a great challenge with regards to colon cancer treatment and targeting the molecular features of this disorder are critical for therapeutic success (3); therefore, understanding the molecular pathogenesis of colorectal cancer is crucial for disease management.

Prolyl 4-hydroxylase, $\beta$ polypeptide $(\mathrm{P} 4 \mathrm{HB})$ is the $\beta$-subunit of prolyl 4-hydroxylase, which acts as an endoplasmic reticulum chaperone to suppress aggregation of misfolded proteins (4). P4HB expression in lung cancer tissues is increased compared with in adjacent tissues and normal lung epithelium, and it has been suggested to induce the growth of lung carcinoma (5). P4HB is also upregulated in high-grade glioma (6). Downregulation of $\mathrm{P} 4 \mathrm{HB}$ decreases temozolomide resistance in malignant glioma via endoplasmic reticulum stress response pathways (7). Our previous study revealed that $\mathrm{P} 4 \mathrm{HB}$ is upregulated in human hepatocellular carcinoma (HCC) tissues, and it promotes HCC cell proliferation and migration (8). These findings indicate that $\mathrm{P} 4 \mathrm{HB}$ may serve an important role in tumorigenesis; however, little is currently known about the effects of $\mathrm{P} 4 \mathrm{HB}$ and its underlying molecular mechanisms in colon cancer.

It is believed that reactive oxygen species (ROS) serve a crucial role in cell apoptosis, and increasing evidence has indicated that ROS regulate the apoptosis of cancer cells (9). ROS function as 'redox messengers' in intracellular signaling and regulation, whereas excessive ROS accelerate cell death $(9,10)$. ROS result in a cellular redox imbalance in various cancer cells, which may be associated with oncogenic stimulation $(11,12)$. Notably, the regulation of ROS may be a promising therapeutic approach against colon cancer. Chen et al (13) demonstrated 
that a novel benzimidazole acridine derivative induced human colon cancer cell apoptosis via the upregulation of ROS. ROS has also been revealed to enhance cisplatin-induced colon cancer cell apoptosis (14). Furthermore, Wang et al (15) revealed that dihydrotanshinone induces p53-independent but ROS-dependent apoptosis of colon cancer cells.

ROS may activate downstream signaling pathways to regulate the phosphorylation status of transcription factors, including signal transducer and activator of transcription (STAT) (16). STAT proteins are recruited to receptors by binding to phosphotyrosine residues in the Src homology 2 domain of the STAT protein (17). STAT is subsequently phosphorylated by Janus kinase 2 and translocated into the nucleus. The STAT family is a group of latent cytoplasmic proteins that regulate various metabolic processes $(18,19)$. The STAT family includes seven structurally and functionally associated proteins: STAT1-4, STAT5a and b, and STAT6 (18). STAT3 is constitutively aberrantly activated in $\sim 70 \%$ of human solid tumors, and it modulates the expression of oncogenes controlling the proliferation and metastasis of tumor cells $(20,21)$. STAT3 is often a downstream effector of numerous oncogenic mutations (22). Substantive evidence has indicated that downregulating STAT3 may mitigate the malignant behavior of cancer cells $(23,24)$.

The present study aimed to investigate the effects of $\mathrm{P} 4 \mathrm{HB}$ on colon cancer. The results showed that $\mathrm{P} 4 \mathrm{HB}$ was significantly upregulated in colon cancer tissues, whereas P4HB knockdown significantly increased cell apoptosis. Furthermore, P4HB knockdown reduced the activation of STAT3 and increased ROS accumulation. These data indicated that $\mathrm{P} 4 \mathrm{HB}$ may inhibit colon cancer cell apoptosis via the ROS/STAT3 signaling pathway.

\section{Materials and methods}

Reagents. N-acetyl cysteine (NAC), an antioxidant, was purchased from Beyotime Institute of Biotechnology (Haimen, China). As described previously (15), colon cancer cells $\left(5 \times 10^{5}\right.$ cells $\left./ \mathrm{cm}^{2}\right)$ were pretreated with NAC $(10 \mathrm{mM})$ for $1 \mathrm{~h}$ at $37^{\circ} \mathrm{C}$ and $5 \% \mathrm{CO}_{2}$.

Clinical tissues. The present study was approved by the Medical Ethics Committee of the Seventh People's Hospital of Shanghai University of Traditional Chinese Medicine (Shanghai, China). All subjects provided written informed consent, and none of them received chemoradiotherapy prior to surgery. From May 2015 to July 2017, 9 patients (5 males and 4 females) with an average age of 52.4 years were enrolled in the present study. Patients that underwent chemoradiotherapy prior to surgery were excluded. Colon cancer tissues and adjacent normal colon tissues were obtained during surgery.

Immunohistochemistry $(I H C)$. According to the manufacturer's protocol, P4HB IHC staining was performed manually using a Bosterbio IHC kit (cat. no. RC1865; Boster Biological Technology, Pleasanton, CA, USA). Briefly, the clinical samples were fixed in $10 \%$ neutral formalin for 2 days at room temperature and embedded in paraffin, after which $3-\mu \mathrm{m}$ sections were cut and mounted onto slides. Slides were incubated at $56^{\circ} \mathrm{C}$, deparaffinized in xylene and dehydrated in a graded series of alcohol. Heat-induced $\left(121^{\circ} \mathrm{C}\right)$ antigen retrieval was conducted with sodium citrate $(\mathrm{pH}$ 6.7) in a pressure-cooker for $30 \mathrm{~min}$ at room temperature. Following washing in wash buffer, peroxidase-blocking reagent (included in IHC kit) was applied for $15 \mathrm{~min}$ at room temperature. Subsequently, sections were incubated overnight at $4^{\circ} \mathrm{C}$ with rabbit anti-P4HB monoclonal antibody (1:100; ab137110; Abcam, Cambridge, UK). Subsequently, a secondary antibody (included in IHC kit) was applied for $30 \mathrm{~min}$ at room temperature. Horseradish peroxidase-streptavidin (included in IHC kit) was used to detect immunoactivity, followed by counterstaining with hematoxylin for $1 \mathrm{~min}$ at room temperature. Under a light microscope (magnifications, x100 and 200; Olympus Corporation, Tokyo, Japan), each section was imaged and semi-quantitatively analyzed according to a previously published method (25).

Cell culture. The HT29 human colon cancer cell line was purchased from the Cell Bank of Shanghai Institute of Biochemistry and Cell Biology, Chinese Academy of Sciences (Shanghai, China). The cells were cultured in Dulbecco's modified Eagle's medium (DMEM; Sigma-Aldrich; Merck KGaA, Darmstadt, Germany) supplemented with $10 \%$ fetal bovine serum (FBS; HyClone; GE Healthcare, Chicago, IL, USA) at $37^{\circ} \mathrm{C}$ and $5 \% \mathrm{CO}_{2}$.

Lentiviral infection. The HT29 human colon cancer cell line was used for lentiviral infection. A lentiviral short hairpin RNA (shRNA) construct targeting P4HB (SHCLNG-NM_000918) was obtained from Sigma-Aldrich (Merck KGaA). Three shRNA sequences targeting $\mathrm{P} 4 \mathrm{HB}$ were designed (Table I). The oligonucleotides were phosphorylated, annealed and cloned into the pLKO.1 vector (Sigma-Aldrich; Merck KGaA), according to the manufacturer's protocol. Briefly, the cells were seeded at $1 \times 10^{5}$ cells/well in a 12 -well plate prior to lentiviral particle infection and incubated with $1 \mathrm{ml}$ DMEM supplemented with $10 \%$ FBS for $6 \mathrm{~h}$. Subsequently, cells were infected with lentiviral particles $\left(1 \times 10^{9}\right)$. This lentiviral transgenic system possessed $>90 \%$ gene transfer effectiveness and a multiplicity of infection of 100 for the inhibition of P4HB expression. After $24 \mathrm{~h}$, the virus-containing medium of infected cells was substituted with DMEM with $10 \%$ FBS, and infected cells were incubated with $1 \mu \mathrm{g} / \mathrm{ml}$ puromycin for $72 \mathrm{~h}$ at $37^{\circ} \mathrm{C}$ and $5 \% \mathrm{CO}_{2}$. Empty lentiviral vectors $\left(1 \times 10^{9}\right)$ were used as a negative control. After the screening for $72 \mathrm{~h}$, the infected cells the subsequent experiments.

Cell proliferation. To evaluate the proliferative ability of colon cancer cells, the cells were seeded into 96-well plates ( $2 \times 10^{3}$ cells/well). Following $24 \mathrm{~h}$, the medium was removed, and the cells were treated with $10 \%$ Cell Counting kit 8 (CCK8; Dojindo Molecular Technologies, Inc., Kumamoto, Japan) in $100 \mu \mathrm{l}$ DMEM without FBS for $2 \mathrm{~h}$ at room temperature. Absorbance at $450 \mathrm{~nm}$, which is directly proportional to the rate of cell proliferation, was measured using a microplate reader.

Assessment of apoptosis. Apoptosis was evaluated using an Annexin V-fluorescein isothiocyanate (FITC)/propidium iodide (PI) dual staining kit (C1052; Beyotime Institute of Biotechnology). Following treatment (shRNA transfection or NAC pretreatment), the HT29 cells $\left(1 \times 10^{6}\right.$ cells) were trypsinized and centrifuged at $400 \mathrm{x}$ g for $5 \mathrm{~min}$ at $4^{\circ} \mathrm{C}$. Cells were then dissolved in $100 \mu \mathrm{l}$ Annexin V-FITC binding buffer, and were 
Table I. Sequences interfering with P4HB.

\begin{tabular}{ll} 
shRNA & \multicolumn{1}{c}{ Sequence $\left(5^{\prime}-3^{\prime}\right)$} \\
\hline shRNA1 & CCGGGCTCCCATTTGGGATAAACTGCTCGAGCAGTTTATCCCAAATGGGAGCTTTTTG \\
shRNA2 & CCGGAGGTGAAATCAAGACTCACATCTCGAGATGTGAGTCTTGATTTCACCTTTTTTG \\
shRNA3 & CCGGGTGTGGTCACTGCAAACAGTTCTCGAGAACTGTTTGCAGTGACCACACTTTTTG \\
ShCtrl & CCTTCTCCGAACGTGTCACGT
\end{tabular}

P4HB, prolyl 4-hydroxylase, $\beta$ polypeptide; shRNA, short hairpin RNA.
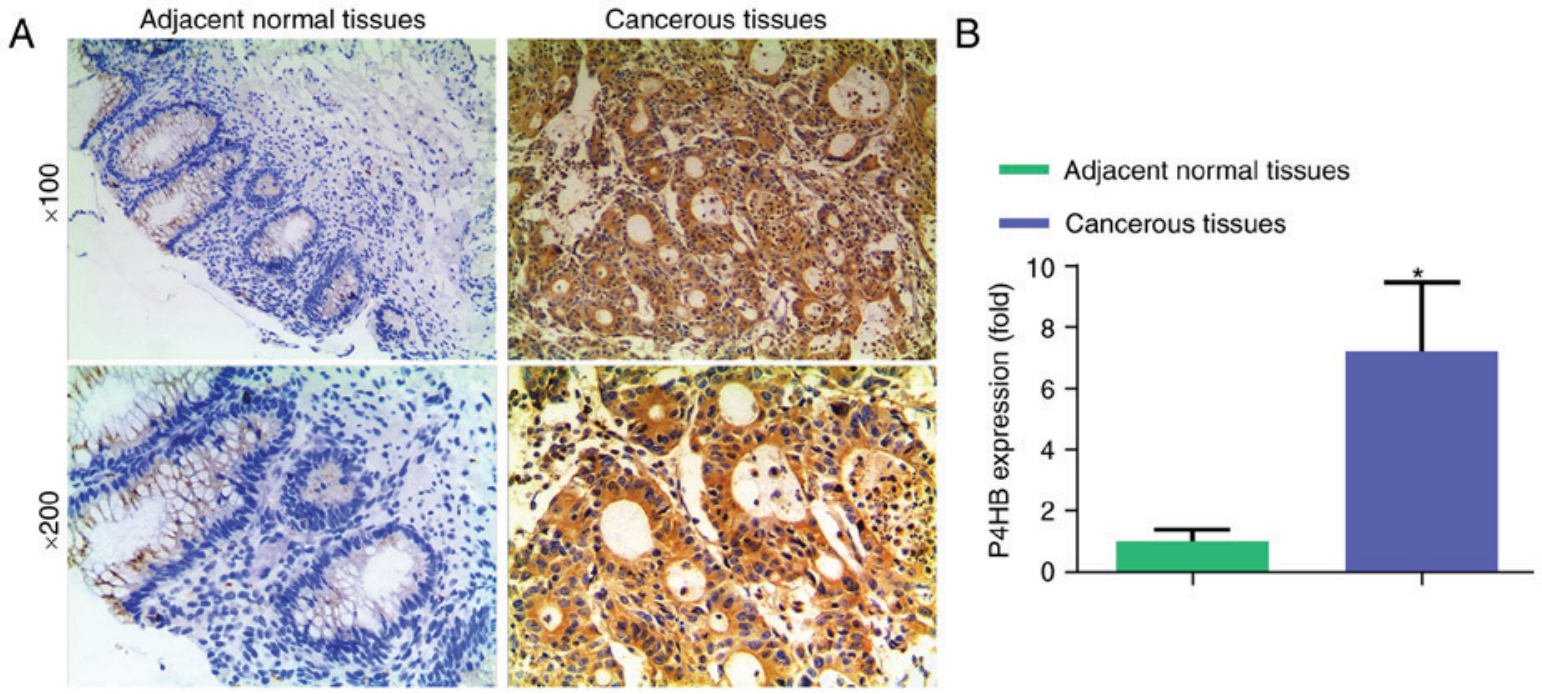

Figure 1. Immunohistochemical staining of P4HB in normal and colon cancer tissues. (A) Representative image of colon cancer tissues and normal adjacent colon tissues, (magnifications, $\mathrm{x} 100$ and 200). (B) Relative semi-quantification of P4HB expression in colon tissues. ${ }^{*} \mathrm{P}<0.05$. P4HB, prolyl 4-hydroxylase, $\beta$ polypeptide.

incubated with $5 \mu \mathrm{l}$ Annexin V-FITC and $5 \mu \mathrm{l}$ PI for $15 \mathrm{~min}$ at room temperature in the dark. Harvested cells were analyzed by fluorescence-activated cell sorting using a flow cytometer.

Detection of ROS. According to a previous study (26), intracellular ROS can be detected using the peroxide-sensitive fluorophore 2',7'-dichlorofluorescein diacetate (DCF-DA; Beyotime Institute of Biotechnology). Briefly, the cells ( $1 \times 10^{5}$ cells) were plated in six-well plates, washed with DMEM without FBS, and incubated with $10 \mu \mathrm{M}$ DCF-DA at $37^{\circ} \mathrm{C}$ for 20-30 min. Fluorescence distribution was detected using a fluorescence spectrophotometer at an excitation wavelength of $488 \mathrm{~nm}$.

Western blot analysis. Cells were lysed in radioimmunoprecipitation assay lysis buffer supplemented with a protease inhibitor (Beyotime Institute of Biotechnology). The concentration of total protein was detected by the BCA method. Whole cell extracts containing equal quantities of proteins $(50 \mu \mathrm{g})$ were separated by $10 \%$ sodium dodecyl sulfate polyacrylamide gel electrophoresis and were then transferred onto a polyvinylidene fluoride membrane. Following blocking in $5 \%$ bovine serum albumin (cat. no. BA7019, Boster Biological Technology) for $1 \mathrm{~h}$ at room temperature, the membranes were incubated overnight at $4^{\circ} \mathrm{C}$ with antibodies specific to $\beta$-actin (1:8,000; cat. no. 4970), phosphorylated (p)-STAT3 (1:1,000; cat. no. 4074), total (t)-STAT3 (1:1,000; cat. no. 12640),
B-cell lymphoma (Bcl)-2 (1:1,000; cat. no. 3498S; all Cell Signaling Technology, Inc., Danvers, MA, USA), cleaved caspase-3 (1:1,000; cat. no. 9661; Abcam), c-Myc (1:1,000; cat. no. 13987) and p53 (1:1,000; cat. no. 2527; both Cell Signaling Technology, Inc.). Horseradish peroxidase-conjugated goat anti-rabbit IgG (1:5,000; cat. no. BA1099; Boster Biological Technology) was applied as a secondary antibody for $1 \mathrm{~h}$ at $37^{\circ} \mathrm{C}$. For all western blots, $\beta$-actin served as an internal control. Protein expression was semi-quantified using Bio-Rad Quantity One software 3.76 (Bio-Rad Laboratories, Inc., Hercules, CA, USA).

Statistical analysis. Statistical analysis was performed using SPSS 18.0 software (SPSS, Inc., Chicago, IL, USA). All experiments were performed at least in triplicate. Data are presented as the means \pm standard deviation. Statistical significance was determined using a two-tailed Student's t-test. Comparisons among multiple groups were analyzed by a one-way analysis of variance, followed by Tukey's post hoc test. $\mathrm{P}<0.05$ was considered to indicate a statistically significant difference.

\section{Results}

$P 4 H B$ levels are lower in normal colon tissues than in colon cancer tissues. To assess the expression levels of $\mathrm{P} 4 \mathrm{HB}$ in normal and cancerous colon tissues, IHC was performed on 
nine clinical specimens. Significantly higher P4HB levels were identified in colon cancer tissues compared with in normal colon tissues (Fig. $1 ; \mathrm{P}<0.05$ ).

Knockdown of P4HB in colon cancer cells by lentiviral infection. To investigate the effects of $\mathrm{P} 4 \mathrm{HB}$, lentiviral vectors were used to downregulate P4HB expression in colon cancer HT29 cells. As shown in Fig. 2, P4HB levels were knocked down using three shRNAs. shRNA3 was chosen for subsequent experiments, as it most effectively downregulated P4HB.

Knockdown of PH4B inhibits proliferation and promotes apoptosis of human HT29 cells. The effects of P4HB on cell proliferation were identified using the CCK8 assay, which revealed that proliferation was significantly reduced in the P4HB-knockdown group compared within the control group (Fig. 3A).

Cell apoptosis was evaluated by Annexin V/PI staining. The percentage of cells undergoing early or late apoptosis was demonstrated in Fig. 3B. Compared with in the control group, apoptosis was significantly increased by P4HB knockdown $(\mathrm{P}<0.05)$. As illustrated in Fig. 4A, the P4HB-knockdown group exhibited markedly higher protein expression levels of p53 and cleaved caspase-3 compared with in the control group. Furthermore, Bcl-2 levels were lower in the P4HB-knockdown group than in the control group.

P4HB knockdown regulates $p$-STAT3 expression and promotes the accumulation of ROS. To explore the molecular mechanism underlying the effects of P4HB on colon cancer cells, ROS generation and STAT3 levels, which are key regulators of colon cancer cell proliferation and apoptosis, were evaluated. P4HB knockdown markedly inhibited activation of p-STAT3 (Fig. 4A) and significantly increased the accumulation of ROS (Fig. 4B). Furthermore, a previous study demonstrated that ROS downregulates p-STAT3 by downregulating c-Myc (27); therefore, the expression of c-Myc was also examined. However, no significant difference was detected in the levels of c-Myc (Fig. 4A), which indicated that ROS may downregulate p-STAT3 levels via other signaling pathways.

Inhibiting ROS accumulation rescues the increased cell apoptosis induced by P4HB knockdown. NAC was used to scavenge intracellular ROS. According to a previous study (15), the cells were pretreated with NAC $(10 \mathrm{mM})$ for $1 \mathrm{~h}$. As demonstrated in Fig. 5A, intracellular ROS levels were decreased by NAC. The levels of apoptosis and apoptosis-associated proteins (Bcl-2, cleaved-caspase-3) were markedly decreased, whereas proliferation significantly increased in response to NAC compared with in cells without NAC (Fig. 5B-D). The increased apoptosis induced by $\mathrm{P} 4 \mathrm{HB}$ knockdown was also reduced by NAC. Finally, NAC effectively reversed the effects of P4HB knockdown on the suppression of p-STAT3 (Fig. 5B).

\section{Discussion}

Colon cancer is one of most lethal malignancies, and there are still great challenges concerning its treatment. According to previous studies, $\mathrm{P} 4 \mathrm{HB}$ is associated with tumorigenesis $(5,6)$. The present study aimed to investigate the effects of P4HB on
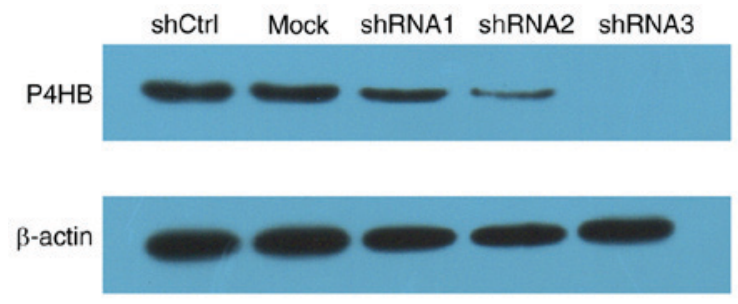

Figure 2. Knockdown of P4HB protein expression by shRNA in HT29 cells. Relative $\mathrm{P} 4 \mathrm{HB}$ protein expression was detected by western blot analysis. Images are representative of three independent experiments. Ctrl, control; P4HB, prolyl 4-hydroxylase, $\beta$ polypeptide; shRNA, short hairpin RNA. Mock, represents untreated cells, which were treated as the control.

human colon cancer. In the present study, compared with in normal colon tissues, P4HB levels were significantly upregulated in colon cancer tissues. P4HB knockdown significantly decreased cell proliferation and increased cell apoptosis in a human cancer cell line. Additionally, downregulation of P4HB suppressed p-STAT3 expression and accelerated the accumulation of ROS. Notably, the increased apoptosis observed after P4HB knockdown was rescued by inhibition of ROS. Notably, the downregulation of ROS could also upregulate p-STAT3 levels. Taken together, these findings suggested that P4HB knockdown may decrease cell proliferation and increase cell apoptosis in a human cancer cell line.

A considerable amount of evidence has indicated that $\mathrm{P} 4 \mathrm{HB}$ is associated with tumorigenesis $(7,8)$. Our previous study reported that $\mathrm{P} 4 \mathrm{HB}$ overexpression promotes HCC cell growth, migration, invasion and epithelial-to-mesenchymal transition, and the knockdown of P4HB expression by small molecules or small interfering RNA may be used as a therapeutic target in $\mathrm{HCC}$ (8). Apoptosis is a gene-directed program that eliminates excess, abnormal cells in vivo. A hallmark of cancer is the capability of cancer cells to resist cell death (28). Therefore, disturbed regulation of apoptosis is a vital factor in tumorigenesis (29). Evasion of apoptosis may have an important role in tumor initiation and therapy resistance (30). p53 is a tumor suppressor, which serves a key role in apoptosis and is frequently inactivated in colon cancer cells (31). In addition, $\mathrm{Bcl}-2$ functions as a suppressor and is a key regulator of apoptosis. Alterations in the $\mathrm{Bcl}-2 / \mathrm{Bax}$ ratio may have an antior proapoptotic effect and may result in caspase activation, thereby inducing apoptosis (27). In the present study, depletion of P4HB upregulated p53 and cleaved caspase-3 expression, and inactivated the expression of Bcl-2. These data indicated that P4HB knockdown increased the apoptosis of colon cancer cells in vitro.

Elevated ROS levels may promote tumor onset and progression by increasing DNA damage and genomic instability (32). ROS-induced oxidative stress can also directly provoke programmed cell death, including apoptosis and autophagy (33). Ding et al (34) revealed that ROS overload prompts apoptosis of colon cancer cells; therefore, targeting ROS in colon cancer cells may be exploited as an anticancer strategy. ROS may activate downstream signaling pathways to regulate the phosphorylation status of transcription factors, including STAT3 (16). Inappropriate activation of STAT3 serves a crucial role in the apoptosis of tumor cells. Chae et al (35) demonstrated that CAY10598 induced apoptosis 

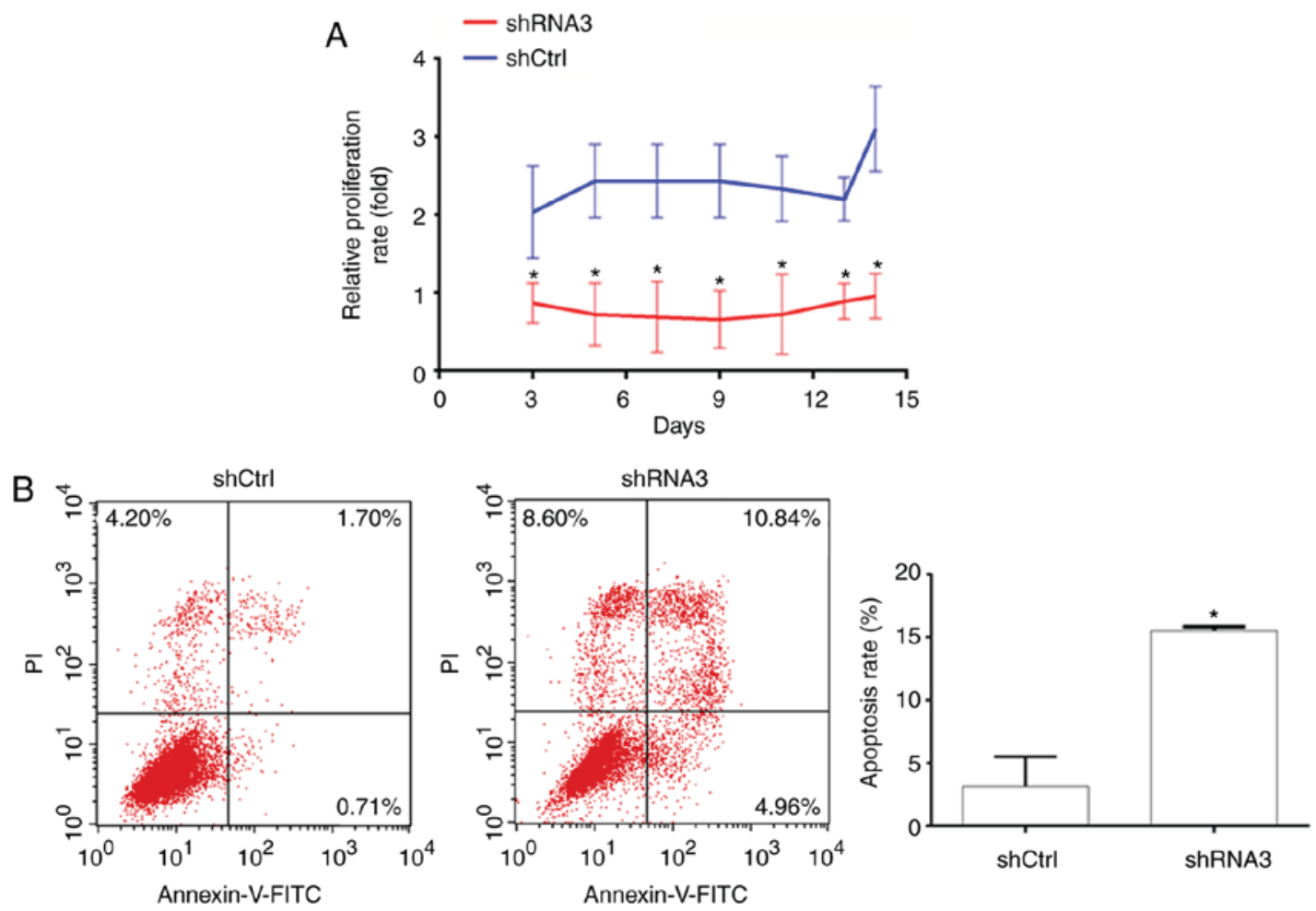

Figure 3. Effects of P4HB knockdown on the viability of HT29 cells. (A) Proliferation rate was assessed by CCK8 detection and (B) apoptosis was analyzed by flow cytometry. Data are presented as the means \pm standard deviation. ${ }^{*} \mathrm{P}<0.05$ vs. the shCtrl group. Images are representative of three independent experiments. Ctrl, control; FITC, fluorescein isothiocyanate; P4HB, prolyl 4-hydroxylase, $\beta$ polypeptide; PI, propidium iodide; shRNA, short hairpin RNA.

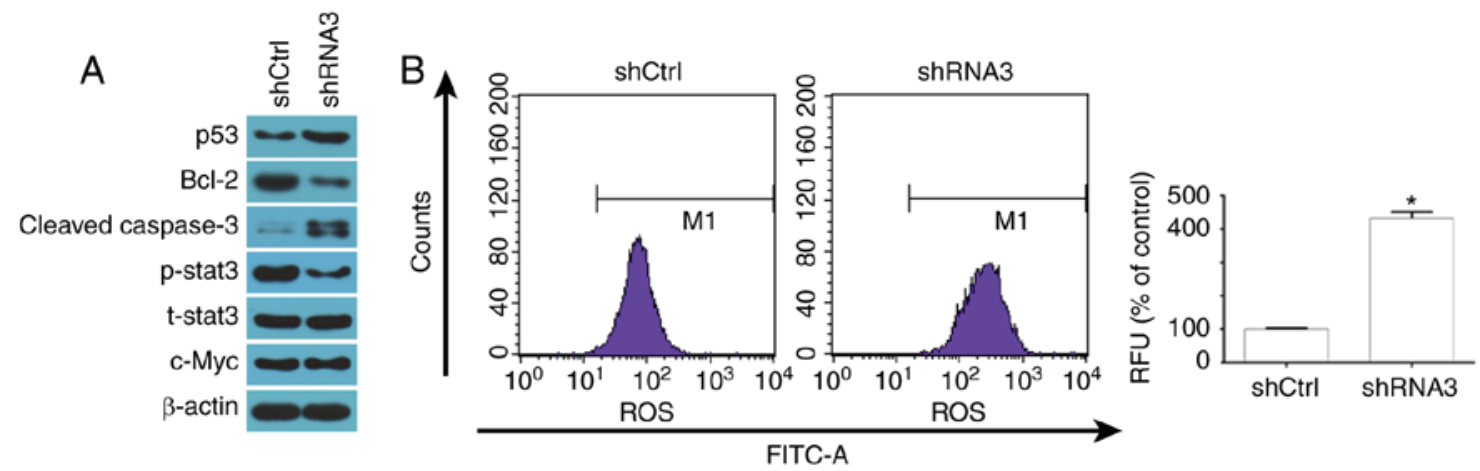

Figure 4. Effects of P4HB knockdown on markers of apoptosis. (A) Representative images of the protein levels of p53, Bcl-2, cleaved caspase-3, p-STAT3, t-STAT3 and c-Myc as assessed by western blot analysis. (B) P4HB knockdown increased the generation of ROS. Images are representative of three independent experiments. Data are presented as the means \pm standard deviation. ${ }^{*} \mathrm{P}<0.05$ vs. the shCtrl group. Bcl-2, B-cell lymphoma 2; Ctrl, control; FITC, fluorescein isothiocyanate; $\mathrm{p}$-, phosphorylated; P4HB, prolyl 4-hydroxylase, $\beta$ polypeptide; RFU, relative fluorescence unit; shRNA, short hairpin RNA; STAT3, signal transducer and activator of transcription 3; t, total.

of colon cancer cells by activating ROS/STAT3 signaling. Kasiappan et al (27) also revealed that the ROS/STAT3 signaling pathway serves an important role in regulating the behaviors of tumor cells. Considering the critical role of ROS/STAT3 in cancer cells, the expression levels of ROS/STAT3 signaling pathway members were investigated in a colon cancer cell line. The present results were consistent with previous reports $(27,35)$. The results demonstrated that P4HB knockdown induced colon cancer cell apoptosis by increasing ROS generation and downregulating STAT3, which may be associated with subsequent activation of the intrinsic apoptosis pathway. Furthermore, blocking the generation of ROS by NAC rescued the increased cell apoptosis induced by P4HB knockdown. Notably, the decreased ROS levels effectively antagonized the effects of P4HB on the activation of p-STAT3. Levels of ROS are controlled at both the level of production and by degradation. The predominant transcriptional response that increases the production of antioxidant proteins in cancer cells is through the activation of nuclear factor (erythroid-derived 2)-like 2 (NRF2). The levels of ROS have been reported to be regulated by antioxidant proteins, such as NRF2 (36). Notably, P4HB may be associated with the expression of NRF2 (36).

There are several limitations in the present study. Firstly, these in vitro results need to be verified in other colon cancer cell lines and in animal models. In addition, it is well known 
A
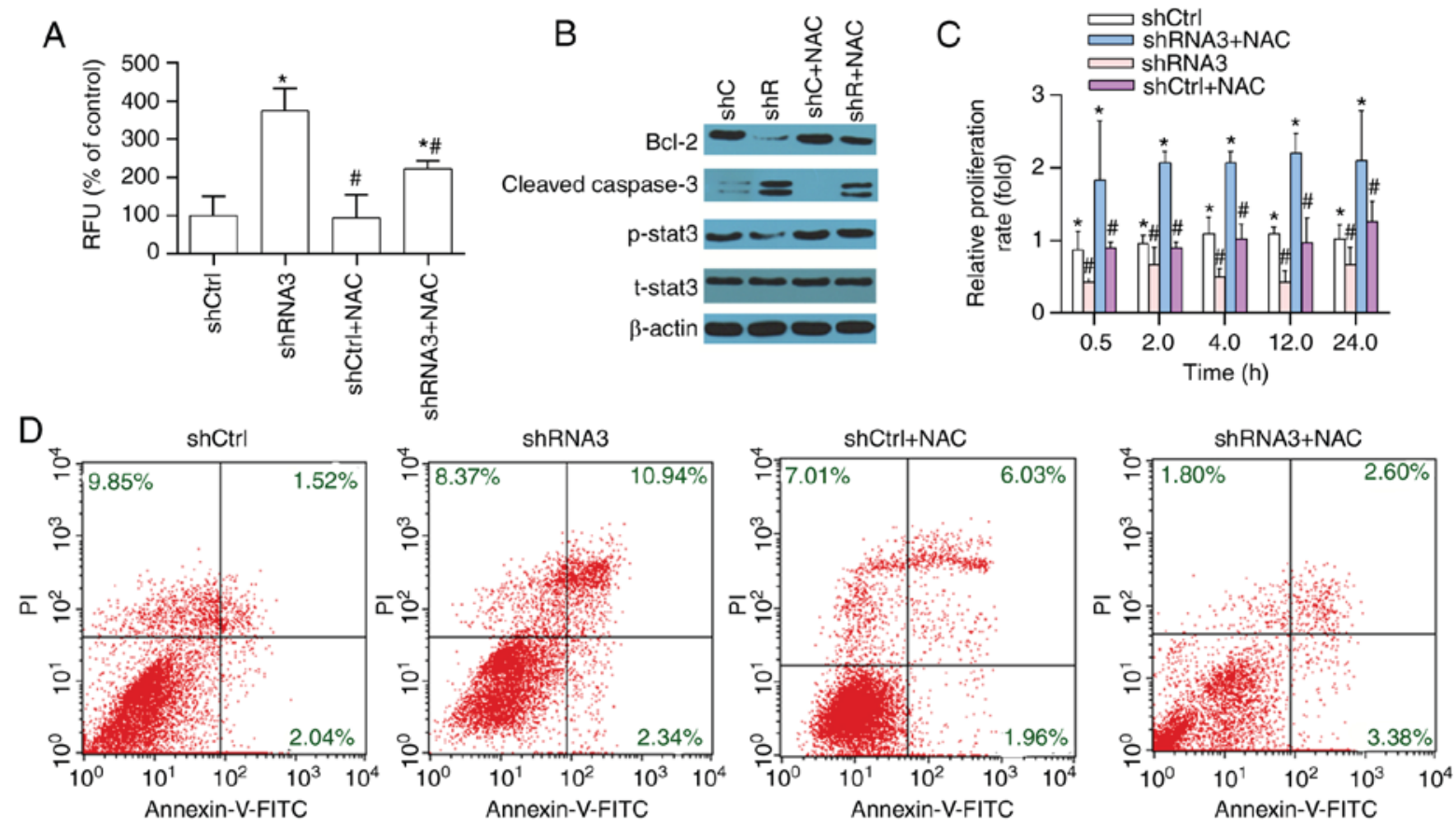

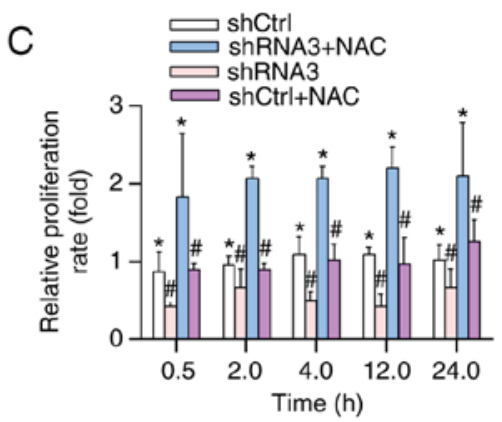

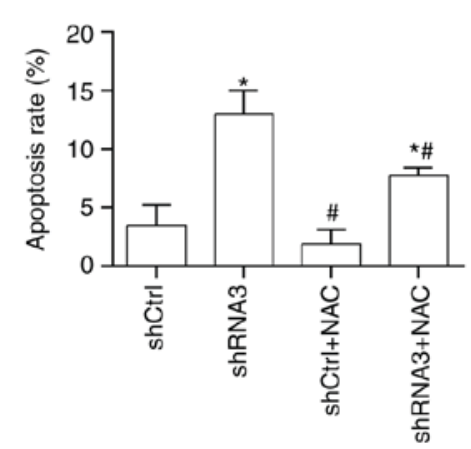

Figure 5. Inhibiting accumulation of ROS reduces apoptosis induced by P4HB knockdown. (A) ROS generation, as measured by flow cytometry. (B and C) Protein levels of Bcl-2, cleaved caspase-3, p-STAT3 and t-STAT3 were assessed by western blot analyses. (D) Annexin V/PI staining was performed to assess cell apoptosis. Images are representative of three independent experiments. All data are presented as the means \pm standard deviation. "P<0.05 vs. the shCtrl group. ${ }^{\#} \mathrm{P}<0.05$ vs. the shRNA3 +NAC group. Bcl, B-cell lymphoma; Ctrl, control; FITC, fluorescein isothiocyanate; p-, phosphorylated; P4HB, prolyl 4-hydroxylase, $\beta$ polypeptide; RFU, relative fluorescence unit; PI, propidium iodide; shRNA, short hairpin RNA; STAT3, signal transducer and activator of transcription 3; t, total.

that $\mathrm{P} 4 \mathrm{HB}$ and its downstream targets may induce ROS accumulation; however, the mechanisms by which $\mathrm{P} 4 \mathrm{HB}$ regulates ROS levels remain unclear. Therefore, further studies are required.

In conclusion, the present data suggested that $\mathrm{P} 4 \mathrm{HB}$ knockdown may induce apoptosis of human colon cancer HT29 cells through the generation of ROS and inactivation of the STAT3 signaling pathway; however, these results require further investigation.

\section{Acknowledgements}

Not applicable.

\section{Funding}

The present study was supported by grants from Shanghai Pudong Commission of Health and Family Planning (grant no. PWRd2016-12), Shanghai Pudong Science and Technology Committee Foundation (grant no. PKJ2016-Y50), Talents Training Program of Seventh People's Hospital of
Shanghai University of TCM (grant nos. BDX2016-01 and QMX2016-04).

\section{Availability of data and materials}

The datasets used and/or analyzed during the current study are available from the corresponding author on reasonable request.

\section{Author'scontributions}

WX and JW designed the experiments. YZ, JY, QZ, QX and LL conducted the experiments. YZ and JY analyzed the data. WX wrote and revised the manuscript.

\section{Ethics approval and consent to participate}

The present study was approved by the Medical Ethics Committee of the Seventh People's Hospital of Shanghai University of Traditional Chinese Medicine (reference no. 2013876). All subjects provided written informed consent. 


\section{Patient consent for publication}

Not applicable.

\section{Competing interests}

The authors declare that they have no competing interests.

\section{References}

1. Ahnen DJ, Wade SW, Jones WF, Sifri R, Mendoza Silveiras J, Greenamyer J, Guiffre S, Axilbund J, Spiegel A and You YN: The increasing incidence of young-onset colorectal cancer: A call to action. Mayo Clin Proc 89: 216-224, 2014.

2. Miller KD, Siegel RL, Lin CC, Mariotto AB, Kramer JL, Rowland JH, Stein KD, Alteri R and Jemal A: Cancer treatment and survivorship statistics, 2016. CA Cancer J Clin 66: 271-289, 2016.

3. Hagan S, Orr MC and Doyle B: Targeted therapies in colorectal cancer-an integrative view by PPPM. EPMA J 4: 3, 2013.

4. Noiva R: Protein disulfide isomerase: The multifunctional redox chaperone of the endoplasmic reticulum. Semin Cell Dev Biol 10 481-493, 1999.

5. Wang SM, Lin LZ, Zhou DH, Zhou JX and Xiong SQ: Expression of prolyl 4-hydroxylase beta-polypeptide in non-small cell lung cancer treated with Chinese medicines. Chin J Integr Med 21: 689-696, 2015

6. Sun S, Wong TS, Zhang XQ, Pu JK, Lee NP, Day PJ, Ng GK, Lui WM and Leung GK: Protein alterations associated with temozolomide resistance in subclones of human glioblastoma cell lines. J Neurooncol 107: 89-100, 2012.

7. Sun S, Lee D, Ho AS, Pu JK, Zhang XQ, Lee NP, Day PJ, Lui WM, Fung CF and Leung GK: Inhibition of prolyl 4-hydroxylase, beta polypeptide (P4HB) attenuates temozolomide resistance in malignant glioma via the endoplasmic reticulum stress response (ERSR) pathways. Neuro Oncol 15: 562-577, 2013.

8. Xia W, Zhuang J, Wang G, Ni J, Wang J and Ye Y: P4HB promotes HCC tumorigenesis through downregulation of GRP78 and subsequent upregulation of epithelial-to-mesenchymal transition. Oncotarget 8: 8512-8521, 2017.

9. Circu ML and Aw TY: Reactive oxygen species, cellular redox systems, and apoptosis. Free Radic Biol Med 48: 749-762, 2010.

10. Lee JE, Park JH, Shin IC and Koh HC: Reactive oxygen species regulated mitochondria-mediated apoptosis in PC12 cells exposed to chlorpyrifos. Toxicol Appl Pharmacol 263: 148-162, 2012.

11. Matés JM and Sánchez-Jiménez FM: Role of reactive oxygen species in apoptosis: Implications for cancer therapy. Int $J$ Biochem Cell Biol 32: 157-170, 2000.

12. Valko M, Rhodes CJ, Moncol J, Izakovic M and Mazur M: Free radicals, metals and antioxidants in oxidative stress-induced cancer. Chem Biol Interact 160: 1-40, 2006.

13. Chen K, Chu BZ, Liu F, Li B, Gao CM, Li LL, Sun QS, Shen ZF and Jiang YY: New benzimidazole acridine derivative induces human colon cancer cell apoptosis in vitro via the ROS-JNK signaling pathway. Acta Pharmacol Sin 36: 1074-1084, 2015.

14. He G,He G, Zhou R, Pi Z,Zhu T, Jiang L and Xie Y: Enhancement of cisplatin-induced colon cancer cells apoptosis by shikonin, a natural inducer of ROS in vitro and in vivo. Biochem Biophys Res Commun 469: 1075-1082, 2016.

15. Wang L, Yeung JH, Hu T, Lee WY, Lu L, Zhang L, Shen J, Chan RL, Wu WK and Cho CH: Dihydrotanshinone induces p53-independent but ROS-dependent apoptosis in colon cancer cells. Life Sci 93: 344-351, 2013

16. Gào X and Schöttker B: Reduction-oxidation pathways involved in cancer development: A systematic review of literature reviews. Oncotarget 8: 51888-51906, 2017.
17. Silver DL, Naora H, Liu J, Cheng W and Montell DJ: Activated signal transducer and activator of transcription (STAT) 3: Localization in focal adhesions and function in ovarian cancer cell motility. Cancer Res 64: 3550-3558, 2004.

18. Darnell JE Jr: STATs and gene regulation. Science 277 $1630-1635,1997$.

19. Levy DE and Darnell JE Jr: Stats: Transcriptional control and biological impact. Nat Rev Mol Cell Biol 3: 651-662, 2002.

20. Yao X, Liu H, Zhang X, Zhang L, Li X, Wang C and Sun S: Cell surface GRP78 accelerated breast cancer cell proliferation and migration by activating STAT3. PLoS One 10: e0125634, 2015.

21. Yeh JE and Frank DA: STAT3-interacting proteins as modulators of transcription factor function: Implications to targeted cancer therapy. ChemMedChem 11: 795-801, 2016.

22. Chai EZ, Shanmugam MK, Arfuso F, Dharmarajan A, Wang C, Kumar AP, Samy RP, Lim LH, Wang L, Goh BC, et al: Targeting transcription factor STAT3 for cancer prevention and therapy. Pharmacol Ther 162: 86-97, 2016.

23. Furtek SL, Backos DS, Matheson CJ and Reigan P: Strategies and approaches of targeting STAT3 for cancer treatment. ACS Chem Biol 11: 308-318, 2016.

24. Nelson EA, Walker SR, Kepich A, Gashin LB, Hideshima T, Ikeda H, Chauhan D, Anderson KC and Frank DA: Nifuroxazide inhibits survival of multiple myeloma cells by directly inhibiting STAT3. Blood 112: 5095-5102, 2008.

25. Hu K and Olsen BR: Osteoblast-derived VEGF regulates osteoblast differentiation and bone formation during bone repair. J Clin Invest 126: 509-526, 2016.

26. Chen MF, Li YJ, Yang TL, Lou B and Xie XM: Losartan inhibits monocytic adhesion induced by ADMA via downregulation of chemokine receptors in monocytes. Eur J Clin Pharmacol 65: 457-464, 2009

27. Kasiappan R, Jutooru I, Karki K, Hedrick E and Safe S: Benzyl isothiocyanate (BITC) induces reactive oxygen species-dependent repression of STAT3 protein by down-regulation of specificity proteins in pancreatic cancer. J Biol Chem 291: 27122-27133, 2016.

28. Hanahan D and Weinberg RA: Hallmarks of cancer: The next generation. Cell 144: 646-674, 2011.

29. Zhang L, Cai Q, Lin J, Fang Y, Zhan Y, Shen A, Wei L, Wang L and Peng J: Chloroform fraction of Scutellaria barbata D. Don promotes apoptosis and suppresses proliferation in human colon cancer cells. Mol Med Rep 9: 701-706, 2014.

30. Yaacoub K, Pedeux R, Tarte K and Guillaudeux T: Role of the tumor microenvironment in regulating apoptosis and cancer progression. Cancer Lett 378: 150-159, 2016.

31. Pavlou D and Kirmizis A: Depletion of histone N-terminal-acetyltransferase Naa40 induces p53-independent apoptosis in colorectal cancer cells via the mitochondrial pathway. Apoptosis 21: 298-311, 2016.

32. Teppo HR, Soini Y and Karihtala P: Reactive oxygen species-mediated mechanisms of action of targeted cancer therapy. Oxid Med Cell Longev 2017: 1485283, 2017.

33. Zhang Y, Du Y, Le W, Wang K, Kieffer N and Zhang J: Redox control of the survival of healthy and diseased cells. Antioxid Redox Signal 15: 2867-2908, 2011

34. Ding Y, Wang H, Niu J, Luo M, Gou Y, Miao L, Zou Z and Cheng Y: Induction of ROS overload by alantolactone prompts oxidative DNA damage and apoptosis in colorectal cancer cells. Int J Mol Sci 17: 558, 2016.

35. Chae IG, Kim DH, Kundu J, Jeong CH, Kundu JK and Chun KS: Generation of ROS by CAY10598 leads to inactivation of STAT3 signaling and induction of apoptosis in human colon cancer HCT116 cells. Free Radic Res 48: 1311-1321, 2014.

36. Lee LC, Weng YT, Wu YR, Soong BW, Tseng YC, Chen CM and Lee-Chen GJ: Downregulation of proteins involved in the endoplasmic reticulum stress response and Nrf2-ARE signaling in lymphoblastoid cells of spinocerebellar ataxia type 17. J Neural Transm (Vienna) 121: 601-610, 2014.

This work is licensed under a Creative Commons Attribution-NonCommercial-NoDerivatives 4.0 International (CC BY-NC-ND 4.0) License. 